\title{
Comorbidities Associated with Febrile Seizures in A Four-Year-Old Boy: Case Report
}

\author{
Mujeebuddin C S ${ }^{1}$, Sai Kumar Yelgar*2, Lekhasree Kasarla ${ }^{2}$ \\ 1. C.E.O and Founder, Clinosol Research Pvt Ltd, Ameerpet, Hyderabad-500038, Telangana, India. \\ 2. Interns, Clinosol Research Pvt Ltd, Ameerpet, Hyderabad-500038, Telangana, India. \\ *Corresponding author's E-mail: saikumaryelgar@gmail.com
}

Received: 19-03-2020; Revised: 02-12-2020; Accepted: 18-12-2020; Published on: 15-01-2021.

\section{ABSTRACT}

A 4-year child was brought by his parents to a tertiary care hospital with a chief complaint of febrile seizures. Because of short duration medical attention is needed after the seizure has ended. Later he developed many complications of febrile seizures which include pyrexia with thrombocytopenia, sinusitis, acute tonsillitis grade 3 with Right Acute Suppurative Otitis Media. The objective of this clinical case report is to highlight these unusual complications due to febrile seizures. Any viral or bacterial illness which causes fever can also provoke febrile seizures. Viral illness and otitis media are the most common sources of fever in children with febrile seizures. This case highlights the challenges paediatricians face, especially in the emergency setting due to the comorbidities of febrile seizures.

Keywords: Febrile Seizures, Sinusitis, Otitis Media, Tonsillitis.

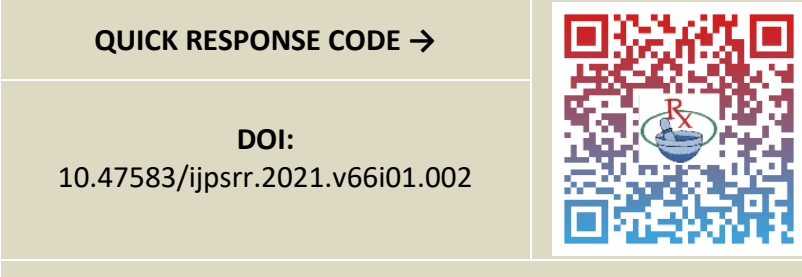

DOI link: $\underline{\text { http://dx.doi.org/10.47583/ijpsrr.2021.v66i01.002 }}$

\section{INTRODUCTION}

F ebrile seizures (FS) are seizures or convulsions that occur in children between six months and six years of age and are triggered by fever ${ }^{1}$. FS are the most common type of convulsions in children. Their prevalence is approximately $3 \%-4 \%$ in while children, $6 \%-9 \%$ in Japanese children, and $5 \%$ and $10 \%$ in Indian children ${ }^{2}$. FS can be extremely frightening for parents, even if they are generally harmless for children, making it important to address parenteral anxiety in the most sensitive manner ${ }^{3}$. The exact causes of FS are still unknown, although some studies indicate a possible association with environmental and genetic factors ${ }^{4}$. Fever is a normal response to infection, and the release of high levels of cytokines during a fever may alter normal brain activity, triggering seizures ${ }^{5}$.

\section{Definition}

The international league against epilepsy (ILAE) defines a febrile seizure as a seizure occurring in childhood after one month of age, associated with a febrile illness that is not caused by an infection of the central nervous system.

FS can be separated into two categories simple and complex. A simple febrile seizure is isolated, brief and generalized. Complex FS is one with focal onset, one that occurs more than once during a febrile illness, or one that lasts more than 10 to 15 minutes $^{6}$

\section{Risk Factors: ${ }^{7,8}$}

Male gender.

A family history of FS.

An elevated peak body temperature.

Certain underlying causes of the fever.

Prenatal and natal complications.

Low serum calcium, sodium or blood sugar.

Microcytic hypochromic anemia.

Iron and zinc deficiencies.

\section{CASE REPORT}

A 4year old boy was admitted to a tertiary care hospital for his complaints of fever since morning and seizures at 9pm today and cough. Child was apparently alright yesterday then he developed fever which is low grade intermittent associated with chills and not rigors which is transiently relived by taking medication. Seizures one episode $9 \mathrm{pm}$ during sleep is GTCS type with involuntary movement of both upper and both lower limbs episode lasts for 5 mins (7-10 minutes) with frothing from mouth, with involuntary micturition and defecation: Child lost consciousness for $10 \mathrm{mins}$ and regained conscious after went to local hospital and diagnosed as febrile seizures (with 102-degree F) and medication given and then they brought to tertiary care hospital with child in post ictal drowsiness for further management.

\section{Antenatal H/O: Consanguineous marriage}

All trimesters uneventful.

Consanguinity is defined as unions contracted between persons biologically related as second cousins or closer. The health complications that are associated with 
consanguinity are caused by the expression of recessive genes inherited from a common ancestor. Further population studies revealed an increased familial clustering of epilepsy among first degree and a lesser extent, second degree relatives.

On day-1 of the hospitalization the physician advised for the following lab parameters: Complete blood picture, Serum electrolytes, Complete urine examination, smear for malarial parasite.

Investigations revealed platelet count- 1 Lakh / cumm [1.54.0 Lakh/ cumm]

Day-1 medications include

Rx-
1)IVF 1/2DNS@50ml/hour [3ml/ kg/hour]
2) Syp $P 2503 \mathrm{ml} / \mathrm{PO} / \mathrm{TID}$
3) Inj. Midaz $1.5 c c+3 c c$ NS slow IV/SOS
4) Tab. Frisium $5 \mathrm{mg} / \mathrm{PO} / \mathrm{BD}$
5) Syp AscorilLS4ml/PO/TID
6) Inj.Ceftriaxone750mg/IV/ BD (100mg/kg/day),
7) Syp. Maxtra 4ml/PO/OD,
8) Dewax drops 2 drops in each ear/BD
9) Inj. Zofer $1.5 \mathrm{mg} / \mathrm{IV} / \mathrm{BD}$
10) PCM Suppository $250 \mathrm{mg}$.

On $2^{\text {nd }}$ day of the hospitalization the physician advised LFT and RFT.

Investigations revealed Alkaline phosphatase (ALP)-245 IU/L(35-126IU/L).

On $3^{\text {rd }}$ day of the hospitalization the physician advised MRIBRAIN PLAIN STUDY. Investigation revealed- Bilateral maxillary and ethmoidal sinusitis.

On $4^{\text {th }}$ day the child was diagnosed with Acute Tonsillitis grade3 and Right Acute Suppurative Otitis Media.

The patient shifted to the ENT ward for the treatment.

On $5^{\text {th }}$ day the complete blood picture revealed Leukocytopenia.

On day $6^{\text {th }}$ child has chief complaint of cough so, syrup Relent Plus 3ml BD was prescribed.

On day $7^{\text {th }}$ and $8^{\text {th }}$ the child has no fresh complaints

On day $9^{\text {th }}$ child has chief complaint of pain in the abdomen and not passing stools in the last 7 days so, injection. Buscopan1cc and Syrup. Lactulose $5 \mathrm{ml}$ PO /HS was prescribed and advised more oral fluids.

Here the upper respiratory tract infections like tonsillitis grade III and the sinusitis are the comorbidities associated degrees with febrile seizures in this patient.
On day $10^{\text {th }}$ fever spike to 101 degrees $F$ and did not pass stools in the last 8 days

On the day of discharge the patient's lab reports are as follows:

Culture sensitivity-revealed Klebsiella Pneumoniae so started Piptaz and amikacin given for 7 days and EEG done

Child is active; accepting orally. No further fever spikes and No seizures.

Discharge Medications were:

1. Syrup Levipil $1.5 \mathrm{ml} / \mathrm{PO} / \mathrm{BD}\{1 \mathrm{ml}=100 \mathrm{mg}\} \times 2$ years

2. Syrup Taxim $04 \mathrm{ml} / \mathrm{PO} / \mathrm{BD}\{5 \mathrm{ml}=100 \mathrm{mg}\} \times 5$ days

3. Syrup $\mathrm{P} 2505 \mathrm{ml} / \mathrm{PO} / \mathrm{SOS}$

4. Syp Ascoril LS $4 \mathrm{ml} \mathrm{PO/TID} \times$ 3days

5. Syp Maxtra 4ml PO/BD x 3 days

\section{DISCUSSION}

Evidence based management for Febrile Seizures in children:

This is a review of the scientific basis derived from various sources, about febrile seizures in children. The doctor may use the information below to give some explanation to the patient's parents.

According to information extracted from the fever seizure consensuses, febrile seizures occur in $2-4 \%$ of children aged 6 months to 5 years. Seizures with fever sometimes occur in infants $<1$ month excluding febrile seizures. If a child $<6$ months or $>5$ years has a febrile seizure, it may be CNS infection or epilepsy that may occur with a fever. children who are experienced seizures without a fever, and then seizures during a fever, are not classified into febrile seizures $^{1}$.

Febrile seizures are divided into 2 types:

Simple febrile seizures, that is: A febrile seizure that lasts a short time, <15 minutes and generally stops by itself. Seizures are Generalized tonic or clonic seizures, with no focal movement. Febrile seizures do not recur within 24 hours.

Complex fever seizures, that is: Seizure lasts $>15$ minutes. Focal or partial seizures of one side are generalized seizures preceded by partial seizures repeats more than once in 24 hours.

The intellectual ability (IQ) and other aspects of brain development do not seem to be affected by febrile seizures, whether it is simple, complex, or recurrent seizures or whether it is simple, complex, or recurrent seizures or whether it is due to infection or after immunization.

Comorbidities associated with febrile seizures are:

$66.4 \%$ viral fever

$34 \%$ URTI 


\section{$8 \%$ Gastritis}

\section{$5 \%$ UTI}

\section{$1 \%$ Otitis Media}

In this case the patient developed febrile seizures due to ante-natal complications.

\section{CONCLUSION}

Parents of the child are consanguineous married. Consanguineous marriage is a major risk factor for epilepsy the child has acquired seizures and other co-morbidities. The educational programs should be conducted for parents of children with febrile seizure who were admitted in hospital should be given leaflets covering the following issues- brief idea about the pathophysiology of the disease, risk of recurrence, course of condition, first aid training and further assessment. It is also needed to increase awareness and help parents to gain better understanding of diseases.

\section{REFERENCES}

1.Paul S.P., Eaton M. At a glance: Febrile convulsion in children. J. Fam. Health Care. 2013; 23: 34-37. Available at https://www.ncbi.nlm.nih.gov/pubmed/23540007

2.Mewasingh L.D. Febrile Seizures: Clinical Evidence. [(accessed on 11 April 2017)]; 2010 available online: www.tinyurl.com/nketvst.
3.Paul S.P., Rogers E., Wilkinson R., Paul B. Management of febrile convulsion in children. Emerg. Nurse. 2015; 23: 18 25. doi:10.7748/en.23.2.18. e1431. Available at : https://www.ncbi.nlm.nih.gov/pubmed/25952398

4.Chung S. Febrile seizures. Korean J. Pediatr. 2014;57: 384-395. Doi:10.3345/kjp.2014.57.9.384. Available at https://www.ncbi.nlm.nih.gov/pubmed/25324864

5.NHS Choices Febrile Seizures- causes. [(accessed on 11 April 2017)];2014 Available Online: www.nhs.uk/Conditions/Febrileconvulsions/Pages/Cause s.aspx

6.Guidelines for epidemiologic studies on epilepsy. Commission on Epidemiology and Prognosis, International League Against Epilepsy. Epilepsia. 1993;34:592-596. [ No authors listed] Available at: https://www.ncbi.nlm.nih.gov/pubmed/8330566

7.Indar kumar S., Jitender S., Lesa D. Evaluation of risk factors associated with First Episode Febrile Seizures. J. Clin. Diagn. Res. 2016;10:10-13. Available at : https://www.ncbi.nlm.nih.gov/pmc/articles/PMC4948495 /\# ffn sectitle

8.Waqar Rabbani M., Ali I., Zahid Latif H. Serum zinc level in children presenting with febrile seizures. Pak.J. Med.Sci. 2013; 29: 1008-1011 Available at: https://www.ncbi.nlm.nih.gov/pmc/articles/PMC3817762 L

Source of Support: None declared.

Conflict of Interest: None declared.

For any question relates to this article, please reach us at: editor@globalresearchonline.net New manuscripts for publication can be submitted at: submit@globalresearchonline.net and submit_ijpsrr@rediffmail.com 